\title{
Hyperbranched phenol-formaldehyde resins
}

\author{
Mieczysław Maciejewski*, Michał Kedzierski, Elżbieta Bednarek \\ Industrial Chemistry Research Institute, ul. Rydygiera 8, P-01-793 Warszawa, Poland
}

Received: 12 March 1997/Accepted: 14 April 1997

\section{Summary}

An approach to synthesis of hyperbranched phenol-formaldehyde resins involving alternating polycondensation is described. Three generations of hyperbranched novolaks were synthesized and characterized. They are enriched in o-p'methylene bridges and therefore well distinguished from normal novolaks by thermogravimetry, IR and NMR spectroscopy measurements.

\section{Introduction}

The synthesis and characterization of dendrimers [1-10] and hyperbranched polymers [11-15] has attracted considerable attention recently. There has been a number of reports concerning different dendrimerization routes. However only very few are believed to be of industrial significance. A special method of encapsulation should be mentioned here $[16,17]$. In respect to commercialization, hyperbranching is probably more valuable.

Our attempts are aimed at the synthesis of hyperbranched phenol-formaldehyde resins, which can be commercial products in the near future. Phenolic resins account for a large part of synthetic plastics, which have gained a stable and important position in technical applications. Nevertheless there have been no essential changes in structural modification of the resins since their discovery. Generally two kinds of phenolic resin may be distinguished: the novolak and resol resins. Both are linear or slightly branched.

Hyperbranching is a process which can provide new structural isomers of phenolic polymers. Such molecules of globular structure can be expected to show some specific properties different from those of linear polymers. These are e.g. lower viscosity [9], and relatively high molecular mass in some cases. Low viscosity can make the resins useful in coatings, while high molecular mass should give phenolics of higher crosslinking rate (higher functionality per molecule).

To produce hyperbranched phenolic resins we applied virtually two reactions (addition to formaldehyde, and condensation with phenol) alternatively, the both being repeated several times.

Alternating hyperbranching can be illustrated schematically in the scheme 1.

The branching process can be continued as long as necessary, if possible, and a novolak or resol of different generation can be isolated alternatively.

In this paper we describe primarily the three cycles of the process, up to the novolak of third generation (we confine ourselves in characterization to novolak products mainly, which are stable substances). It must be emphasized, that nobody can expect the alternating phenol-formaldehyde polycondensation process to be the only one, which occurs according to the above scheme exclusively. Intermediate resin molecules react also with each other to make the growth of a molecule more complex. It happens most probably in the reactions (b), (d) and (f). Therefore, we followed two approaches: 1 . using a large excess of phenol to reduce the side reaction, and 2 . using a small excess to make the process economical.

\footnotetext{
* Corresponding author
} 
Scheme 1

(a)

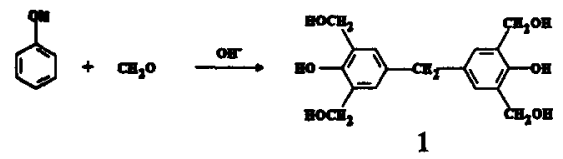

(b)

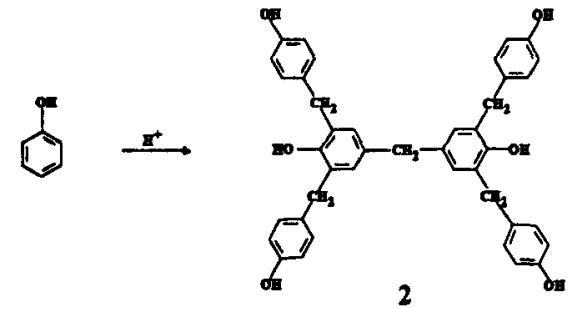

(c) $2+\mathrm{Cm}_{2} \mathrm{O} \stackrel{\text { OH }}{\longrightarrow}$

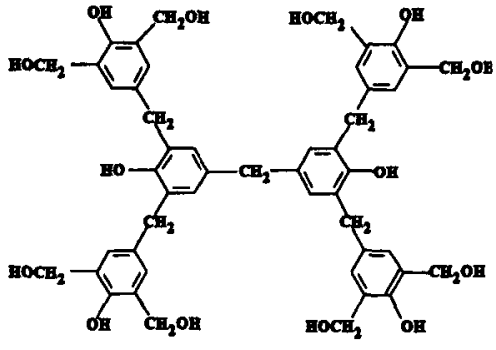

3

$3 \underset{\text { (d) }}{\stackrel{\mathrm{PhOH}, \mathrm{H}^{+}}{\longrightarrow}}$ 4 $\frac{\mathrm{CH}_{2} \mathrm{O}, \mathrm{OH}}{(\text { e })}$ 5 $\frac{\mathrm{PhOH}, \mathrm{H}^{+}}{(\mathrm{f})}$ 6

1 -idealized initial resol (a core substance for the branching process)

2 - idealized hyperbranched novolak of first generation

3 - idealized hyperbranched resol of first generation

4,6 - hyperbranched novolaks of second and third generation

5 -hyperbranched resol of second generation

\section{Experimental part}

\section{Materials}

Phenol, formaldehyde (as 36\% formalin), natrium hydroxide and acetic acid were commercially obtained and used without further purification.

\section{Synthesis}

The initial resol resin was prepared (stage (a)) under molar ratio phenol - formaldehyde - sodium hydroxide 1:4:0.05. Synthesis was carried out at the boiling temperature to a degree of condensation defined by water tolerance equal to $10 \mathrm{~mL}$.

Water tolerance - amount of added water causing a permanent cloudiness of $5 \mathrm{~mL}$ of resin 
The reaction product (contained about $9.7 \%$ free formaldehyde and $0.1 \%$ free phenol) was then added dropwise to the phenol (adjusted previously to $\mathrm{pH}$ about 1 with hydrochloric acid) at $80-90^{\circ} \mathrm{C}$ under vigorous stirring. Then reaction mixture was heated to reflux and condensation was carried out at reflux for $60 \mathrm{~min}$ (stage (b)). The molar excess of phenol to formaldehyde was varied from 1:0.8 to 10:1. The unreacted phenol was removed by vacuum distillation followed by steam distillation.

The same reaction conditions were applied to further condensation stages ((d) and (f)) except for larger molar excess of phenol to formaldehyde (above 2:1).

Further addition stages $((\mathrm{c})$ and $(\mathrm{e}))$ were carried out at a molar ratio of formaldehyde to a phenol unit of a resin equal to 3:1 and in the presence of $0.2-0.5$ moles of sodium hydroxide per 1 mole of phenol. A reaction temperature range 60 to $70^{\circ} \mathrm{C}$ - was lower than at stage (a) in order to avoid undesirable polycondensation side reaction. After assumed time (from 30 to $120 \mathrm{~min}$ ) the reaction mixture was cooled and solid resol resin was precipitated by addition of excess of acetic acid. The course of addition reaction was observed with the aid of ${ }^{1} \mathrm{H}-\mathrm{NMR}$ spectroscopy.

\section{Results and discussion}

Synthesis

Usual conditions $(\mathrm{NaOH}$ as a catalyst) of phenol-formaldehyde addition reaction were applied to produce the resol resin - a core substance for the branching process (stage (a)) - as well as branched resols (stages (c) and (e)). The resols were used directly in the reaction with phenol ((b),(d),(f)) or previously precipitated from the reaction mixtures by neutralization with acetic acid. The precipitation allowed us to prevent unreacted formaldehyde from the reaction with phenol at the next stage.The reaction would complicate additionally the branching process otherwise.

Table 1. Some properties of hyperbranched novolak resins

\begin{tabular}{ccccc}
\hline Novolak & $\begin{array}{c}\text { Generation } \\
\text { number }\end{array}$ & $\begin{array}{c}\text { Number-average } \\
\text { molecular weight } \\
(\mathrm{VPO})\end{array}$ & $\begin{array}{c}\text { Melting point } \\
\left({ }^{\circ} \mathrm{C}\right)\end{array}$ & $\begin{array}{c}\text { Intrinsic viscosity } \\
(\mathrm{mL} / \mathrm{g})\end{array}$ \\
\hline $\mathrm{N} 1$ & conventional & 750 & $86-92$ & 5.5 \\
$\mathrm{R} 3-\mathrm{F} 1$ & 1 & 860 & $102-105$ & 4.8 \\
$\mathrm{R} 3-\mathrm{SF}$ & $1^{\mathrm{a})}$ & 1700 & $120-129$ & 4.7 \\
T42-F & 2 & 2400 & $165-175$ & - \\
T44-F & 2 & 3400 & $174-186$ & 19.5 \\
P52-F & 3 & doesn't melt, partially soluble in DMSO,DMF \\
and aqueous alkaline solutions
\end{tabular}

a) obtained from resol precipitated

Strong acidic conditions $(\mathrm{HCl})$ were used in reactions of resols with phenol. Unreacted phenol from novolaks was removed under vaccuum and by steam distillation - to prevent disturbing branching process at stages (c) and (e). Under applied conditions cross-linking was easily excluded at condensation stages (b) and (d) even in these cases, when small molar excess of phenol to hydroxymethyl groups was used (1:0.8 for the stage (b)). The excess was approximately the same as for conventional novolak condensation processes. Basic properties of particular products obtained are shown in Table 1. It is worth while noticed that intrinsic viscosity of first generation novolak R3-SF is even less than that of conventional one N1 in spite of much higher molecular weight of the first. It corresponds very well to globular structure of the product. 
a
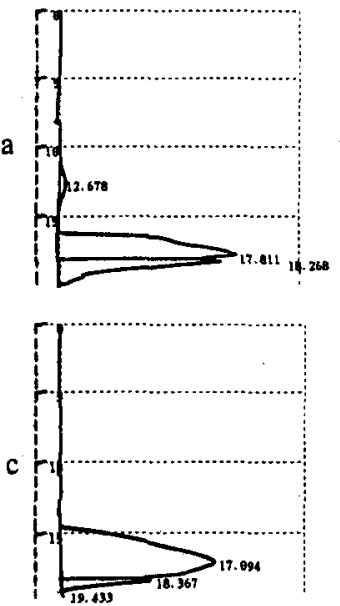

b

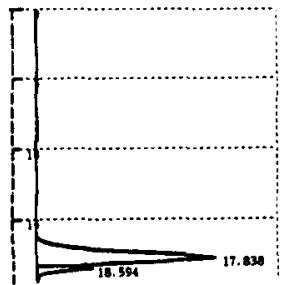

d

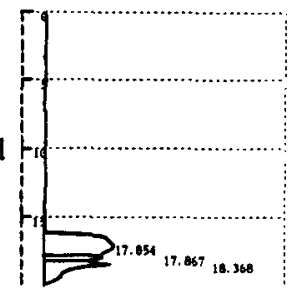

Fig 1. Gel permeation chromatograms of novolak resins: a - conventional b,c - hyperbranched novolak (first generation) $d$ - hyperbranched novolak (second generation)

\section{Characterization}

GPC

Generally phenol-formaldehyde resins are not homogenous in respect to molecular mass distribution. It is clearly shown in the GPC chromatogram of a conventional novolak resin (Fig la). Several separate fractions can be observed there. Obtained in our experiments branched novolaks exhibit approximately the same homogeneity in the case of the second generation of branching (Fig 1d) - independently on the way they have been obtained.

Nevertheless the first generation hyperbranched novolak can be considered roughly homogeneous unless small amounts of 4,4' - dihydroxydiphenylmethane are taken into account, although their chromatograms (Fig 1c) show yet considerable broad molecular mass distribution with slightly irregular line.

As can be expected the high homogeneity was observed for the hyperbranched novolak of the first generation, obtained at a large excess of phenol in relation to a core resol $\left(10: 1\right.$ of phenol to $-\mathrm{CH}_{2} \mathrm{OH}$ groups of the resol) (Fig.1b).

At this moment we can not discuss molecular mass distribution of the third generation novolaks because of their limited solubility. Anyway, the alternative phenol-formaldehyde reactions follow the branching process rule of broadening molecular distribution towards higher generations, which was observed earlier [5]. The extra turbulence in molecular mass distribution comes obviously from polycondensation side reaction, which compete with the branching and can not be avoided, especially when process is carried out in an economical fashion.

\section{$T G$}

On contrary, hyperbranched novolaks exhibit increasing homogeneity towards higher generations in respect to their chemical structure, expressed by thermogravimetrical measurements. TG curves show structural uniformity of these substances (Fig 2 b) when compared with conventional novolak (Fig $2 a$ ).

Two steps of decomposition of the conventional novolak can be distinguished in the curve $2 \mathrm{a}$. This must be connected with a difference in thermal stability of two groups of structural units of the novolak. 


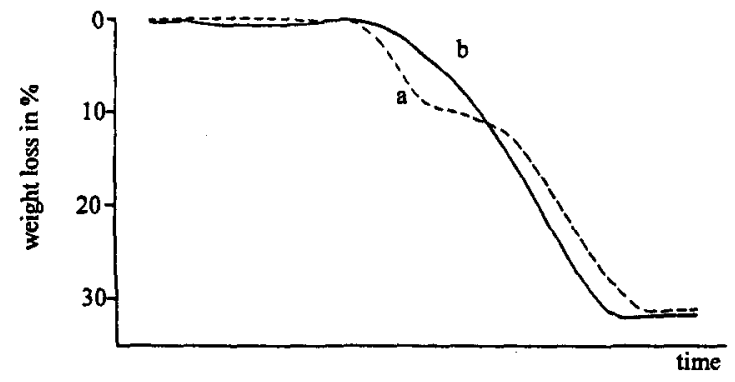

Fig. 2. Thermogravimetric analysis curves of novolak resins: $a$ - conventional $b$ - hyperbranched novolak (third generation)

The character of curve $2 \mathrm{~b}$ (branched novolak of second generation) is quite different from that of conventional novolak. This is more smooth and corresponds probably to enrichment in a third group of structural units, whose thermal stability is between those two dominated in conventional novolak. The structural units of the third group might be o-p' methylene linkage discussed below.

Another hyperbranched product obtained from a conventional novolak as a core (starting) substance, which will be discussed elsewhere, exhibits the smooth TG relation already at the first branching generation. It should be emphasized, that the TG relation is not affected by the molecular mass of the sample. The shape of curves is approximately the same for all conventional novolaks examined, having molecular mass 750, 1200 and 1600. This is consistent with previous investigations on thermal stability of phenolics in respect to different methylene linkages [18].

Hence the smoothness of the TG curves of hyperbranched novolaks is associated rather with their branched structure (enriched in o-p' methylene linkages) then with the molecular mass.
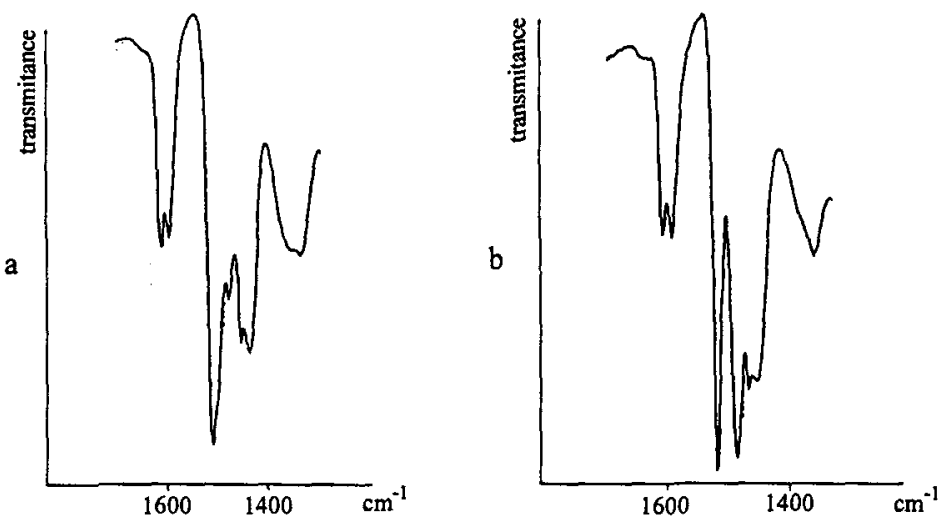

Fig.3. IR spectra of novolak resins: $a$ - conventional $b$ - hyperbranched novolak (third generation) 
IR

Hyperbranched novolaks can easily be distinguished from ortho and conventional ones by using IR spectroscopy.

Spectra of the first generally are similar to those of conventional novolaks, but some considerable differences are noticed (Fig. $3 \mathrm{~b}$ ). In the range $460-700 \mathrm{~cm}^{-1}$ there is only one sharp band $\left(510 \mathrm{~cm}^{-1}\right.$ ) dominating profoundly in the region.

The band covering two peaks at 1336 and $1356 \mathrm{~cm}^{-1}$ in the spectra of conventional novolak is narrowing in the spectra of hyperbranched ones towards the higher generations, becoming almost single sharp band at $1334 \mathrm{~cm}^{-1}$ for the third generation product.

Hyperbranching causes considerable changes in the absorption at $1475 \mathrm{~cm}^{-1}$, which is very weak for conventional novolaks. It is growing profoundly for higher generations of hyperbranched product. The absorption band at $1475 \mathrm{~cm}^{-1}$ can probably be ascribed to methylene group C-H scissor deformation [19]. It is not present in the spectrum for 4,4'-dihydroxydiphenylmethane (p,p'-methylene linkage) and is weak again in spectra of orthonovolaks (predominantly $0,0^{\prime}$-methylene linkages). The band must therefore be associated with the $0, p^{\prime}$-methylene linkages, in which branching molecules are enriched with increase in the generation number.

It must be emphasized, that all the conventional novolaks, obtained by us (Fig 3a) as well as those commercial ones [20] have IR spectra of exactly the same finger prints. Hence the IR spectroscopy is a powerful tool to distinguish hyperbranched and other novolaks from each other.

\section{NMR}

${ }^{13} \mathrm{C}$-NMR measurements confirm the growing number of $0, p$ '-methylene linkages towards higher generation products.

It is clearly shown in the Fig. 4 that intensity of the signal at $\delta=36 \mathrm{ppm}$ which corresponds to carbon atoms of 0 -p'methylene linkages [21], is growing from the conventional novolak towards higher generation of hyperbranched ones.

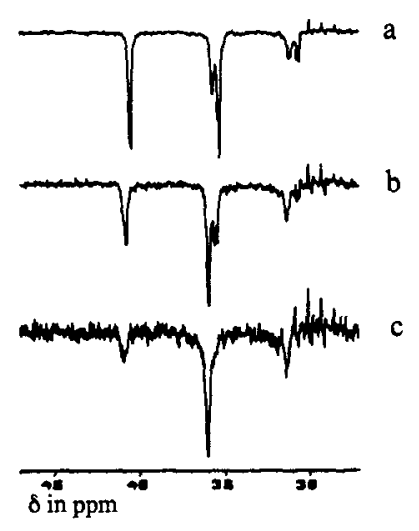

Fig.4. ${ }^{13} \mathrm{C}-\mathrm{NMR}$ spectra of novolak resins: $a$ - conventional $b$ - hyperbranched novolak (first generation) $\mathrm{c}$ - hyperbranched novolak (second generation)

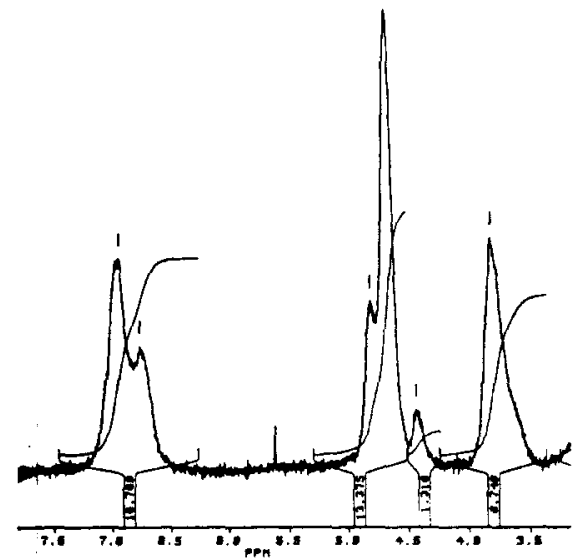

Fig.5. ${ }^{1} \mathrm{H}-\mathrm{NMR}$ spectrum of hyperbranched resol (second generation) 
While intensities of o-p' and p-p' methylene signals $(\delta=36 \mathrm{ppm}$ and $\delta=40.9 \mathrm{ppm}$, respectively [21] are comparable with each other in the case of conventional novolak (Fig.4a), methylene o-p' signal predominates significantly for the second generation products (Fig.4c). Methylene $0-0^{\prime}$ signal $(\delta=31.4 \mathrm{ppm})$ remains weak throughout the novolaks investigated. Effectiveness of branching process can easily be estimated by ${ }^{1} \mathrm{H}-\mathrm{NMR}$ analysis [22] of a resol as intermediate on the course for hyperbranched novolak of the first generation (R3-F1, table 1) to that of second one (T42-F). ${ }^{1} \mathrm{H}-\mathrm{NMR}$ spectrum (Fig. 5) of the resol integrates for 16 aromatic protons $(\delta=6.5-7.5 \mathrm{ppm}), 13$ protons of $\mathrm{Ar}-\mathrm{CH}_{2}-\mathrm{Ar}$ type $(\delta=3.8 \mathrm{ppm})$, and 22 protons of $\mathrm{Ar}-\mathrm{CH}_{2} \mathrm{OH}$ type $(\delta=4.4-4.8 \mathrm{ppm})$ that corresponds approximately to $16: 14: 20$ of respective hydrogens in the octanuclear novolak $\mathrm{R} 3-\mathrm{F} 1$, in which all the active hydrogens (o.p.) have been replaced by hydroxymethyl groups. Small amounts of the $\mathrm{Ar}\left(\mathrm{CH}_{2} \mathrm{O}\right)_{2} \mathrm{H}(\delta=4.8 \mathrm{ppm})$ makes the slight excess of hydrogens in the $-\mathrm{CH}_{2} \mathrm{OH}$ region of the spectrum. In turn all the hydroxymethyl groups were transformed into methylene bridges by reaction with phenol (stage (d)) to produce hyperbranched novolak of second generation T42-F. There is no other $-\mathrm{CH}_{2}$ - signal, than $\mathrm{Ar}-\mathrm{CH}_{2}-\mathrm{Ar}$ in the ${ }^{13} \mathrm{C}-\mathrm{NMR}$ spectrum of T42-F. It means an average novolak molecule consisted of 8 phenol units possess 10 active branching points to make the branching process extremely effective. A little higher molecular weight (2400) of the T42-F then calculated one (1920) show that a few reactive hydrogens remained in R3-F1 unchanged that caused additional increase in molecular weight by coupling some branched molecules.

Further investigations on synthesis and characterization of phenolic and related hyperbranched resins are going on and will be reported later.

\section{Measurements}

The $100 \mathrm{MHz}{ }^{1} \mathrm{H}-\mathrm{NMR}$ and $25.2 \mathrm{MHz}{ }^{13} \mathrm{C}-\mathrm{NMR}$ spectra were taken for samples in $5 \mathrm{~mm}$ tubes with Bruker WP-100 SY instrument at room temperature and under standard conditions. Samples were dissolved in acetone- $\mathrm{d}_{6}$ (occasionally DMSO-d6). TMS was used as an internal reference. IR spectra were recorded with $\mathrm{KBr}$ pellets on a Perkin Elmer System 2000 FT-IR spectrometer. TG measurements were performed with a Q-1500 D (MOM Budapest) derivatograph. Novolak samples were heated at a rate of $5^{\circ} \mathrm{C} / \mathrm{min}$ in air.

Gel permeation chromatography (GPC) analyses were carried out on a Shimadzu C-R4A Chromatopac equipped with two columns $(250 \times 7.4 \mathrm{~mm}$ ). The columns were filled with Microstyragel $5 \mathrm{~m}$ (mixed bed).Tetrahydrofuran as eluent and refractive index detector were used. The flow rate was $1 \mathrm{~mL} / \mathrm{min}$; solution concentrations were in the range of $0.15-0.2 \% \mathrm{wt} .-\%$. GPC calibration curve was obtained using narrow-dispersity polystyrene standards.

Average-number molecular weights of novolaks were determined with Hewlett Packard 302 Vapor Pressure Osmometer (with tetrahydrofuran as a solvent at $36^{\circ} \mathrm{C}$ ).

The intrinsic viscosity of the novolak resin solutions in ethanol was measured by means of an automatic viscometer AVS 400 Schott Geräte at $30^{\circ} \mathrm{C}$. The measurements were carried out on solutions with concentrations ranging from 5 to $20 \mathrm{~g} / \mathrm{L}$, with preliminary filtration.

\section{References}

1) M. Maciejewski, J.Macromol.Sci.Chem., A17,689(1982)

2) P.-G. de Gennes, H. Hervet, J.Phys.Lett., 44, L351 (1983)

3) M. Maciejewski, J. Jezierski, J.Inclusion.Phenom., 2, 417 (1984)

4) D.A. Tomalia, H. Baker, J. Dewald, M. Hall, G. Kallos, S. Martin, J. Roeck, J. Ryder, and P. Smith, Polym. J., 17, 117 (1985)

5) C.J. Hawker, and J.M.J. Fréchet, J.Am.Chem.Soc., 112, 7638 (1990)

6) G.R. Newkome, C.N. Moorfield, G.R. Baker, Aldrichimica Acta, 25, 31 (1992)

7) D.A. Tomalia, A.M. Naylor, W.A. Goddard, III, Angew.Chem.Int.Ed.Engl., 29, 138 (1990) 
8) H. Galina, G. Groszek, Polimery, 40, 24 (1995)

9) E.E.M. de Brabander-van den Berg, E.W. Meijer, Angew.Chem., 105, 1370 (1993)

10) C.J.Hawker, P.J.Farrington, M.E.Mackay, X.L.Wooley and J.M.J.Fréchet, J.Am.Chem.Soc. 117, 4409 (1995)

11) M. Gauthier, M. Moller, Macromolecules, 24, 4548 (1991)

12) K.E. Uhrich, C.J. Hawker, J.H.J. Fréchet, S.R. Turner, Macromolecules, 25, 4583 (1992)

13) H.R. Kricheldorf, O. Stöber, Macromol. Rapid Commun., 15, 87 (1994)

14) M. Johansson, A. Hult, J. Coat. Technol., 67(849), 35 (1995)

15) E. Malmström, M. Johansson, A. Hult, Macromolecules, 28, 1698 (1995)

16) J.F.G.A. Jansen, E.W. Meijer, E.M.M. de Brabander-van der Berg, J.Am. Chem. Soc., 117(15), $4417(1995)$

17) J.F.G.A. Jansen, E.M.M. de Brabander-van der Berg, E.W. Meijer, Science, 265, 1226 (1994)

18) H.Horiuchi, A.Fukuda, Weyerhaeuser Sci. Symp., 2, 189 (1979)

19) N.L. Alpert, W.E. Keiser, H.A. Szymanski, "IR.Theory and Practice of Infrared Spectroscopy", Plenum Press, New York 1970

20) D.O. Hummel, F.Scholl, "Atlas of Polymer and Plastics Analysis", vol.2, Verlag Chemie, Weinheim 1984

21) A.J. de Breet, W.Dankelman, W.G.B.Huysmans, J. de Wit, Angew.Makromol.Chem. 62, 7 (1977)

22) J.C. Woodbrey, H.P. Higginbottom, H.H. Culbertson, J. Polym. Sci. Part A, 3, 1079 (1965) 